
\title{
28 Research Square \\ Effects of propofol on mammalian central and peripheral circadian clocks
}

\section{Hongni Tian}

Army Medical University

\section{Ziqing Yu}

National Institute of Biological Sciences

\section{Xiwen Zhu}

Chongqing Medical University

\section{Yuanjing Chen}

Chongqing Medical University

\section{Qian Ren}

Chongqing Medical University

\section{Sheng-Qing Lv}

Army Medical University

\section{Eric Erquan Zhang}

National Institute of Biological Sciences

\section{Tiande Yang}

Army Medical University

\section{Huang He ( $\square$ 13708385559@163.com )}

Chongqing Medical University https://orcid.org/0000-0002-0289-1201

\section{Research article}

Keywords: Circadian clock; Propofol; Liver; Hypothalamus

Posted Date: April 19th, 2019

DOI: https://doi.org/10.21203/rs.2.9258/v1

License: (c) (1) This work is licensed under a Creative Commons Attribution 4.0 International License. Read Full License 


\section{Abstract}

Background Circadian rhythm has a significant correlation with the occurrence and development of many diseases. Studies have shown that the anesthetic agent propofol can alter the rhythms of body temperature and activity in rats. Methods U2OS cells and ex vivo liver tissue were treated with different concentration of propofol, followed by recording the oscillation of the circadian clock. And two month-old mice were exposed to propofol $(10 \mathrm{mg} / \mathrm{kg}$ and $20 \mathrm{mg} / \mathrm{kg})$ or vehicle, detecting the expression of the clock genes. Results The results showed that propofol reduced the amplitude and lengthened the period of Per2 oscillation. Treatment with $10 \mathrm{mg} / \mathrm{kg}$ propofol significantly increased the expression of D-box binding PAR BZIP transcription factor ( $\mathrm{Dbp}$ ) and clock circadian regulator (Clock) in the liver. Treatment with 20 $\mathrm{mg} / \mathrm{kg}$ propofol significantly decreased expression of cryptochrome circadian regulator 1 (Cry1), Dbp, nuclear receptor subfamily 1 group D member 1 (Nr1d1) and Clock and significantly increased the hypoxia signaling pathway genes hypoxia inducible factor 1 subunit alpha (Hif-1a), Egl-9 family hypoxia inducible factors Egln1, Egln2 and Egln3 in the hypothalamus. Conclusion The above results indicate that the general anesthetic propofol can change the circadian clock of ex vivo and in vivo mammalian liver tissues.

\section{Background}

The clinical data showed that in patients with surgical aortic valve replacement, the incidence of postoperative complications in patients undergoing surgery in the morning was 2 times higher than that for patients undergoing surgery in the afternoon [1]. Therefore, it is proposed that the difference in postoperative complications of surgical aortic valve replacement is related to the circadian clock.

Almost all living organisms on the earth have a circadian clock of approximately $24 \mathrm{~h}$, which is evolved to adapt to the earth rotation period [2,3]. Except for regulated by the environment factors like light and temperature, the circadian clock is controlled by clock genes to maintain its stability. The expression of clock genes is represented by a sinusoidal oscillation; therefore, period, amplitude and phase are used to describe circadian clock [4]. The core clock is composed of a transcription-translation feedback loops engaged with positive (CLOCK and BMAL1) and negative ( CRYPTOCHROME and PERIOD) factors [5]. In mammals, the central pacemaker in the hypothalamic suprachiasmatic nuclei (SCN) coordinates peripheral tissue clocks to perform physiological functions[6].

While the central clock in SCN is stable, which can be regulated by light and some metabolites[7], the peripheral clock is relatively independent of $\mathrm{SCN}$ and can be regulated by more factors, like temperature, chemicals and feeding. A research has shown that dexamethasone does not affect the expression of clock genes in the SCN but that it can change the phase of the clock genes in liver, kidney, and heart [8] .Clinical study mentioned above indicated that the cause of difference in postoperative complications may be related to the fluctuant expression of the intrinsic clock gene Rev-Erba(Nr1d1) in the morning and afternoon[1]. However, it did not consider the effects of various drugs and external environmental factors on circadian clock during the surgery, additionally, the difference between central and peripheral clock 
was not taken into consideration. During the surgery, general anesthesia is an important and essential factor, which may influence the circadian clock.

As one of the most commonly used anesthetics in clinical treatment, propofol is used not only in painless gastrointestinal endoscopy as a low dose but in continuous intraoperative perfusion as well. And propofol can act on both the central nervous system and peripheral tissues. The circadian clock of peripheral tissues is regulated by the SCN and self-regulated as well[9]. For peripheral tissues, selfregulated circadian clock is most important for the maintenance of the function [10]. Furthermore, after mice were anesthetized with propofol, their respiratory rate slowed, which may affect the hypoxia signaling pathway. Previous studies have confirmed that the reciprocal regulation between the circadian clock and hypoxia signaling at the genome level in mammals [11].

Summarizing the current research, it was found that propofol can alter the body temperature rhythm and locomotor activity rhythm in rats $[12,13]$. It was also reported that $6 \mathrm{~h}$ after being anesthetized with propofol, the expression of D-box binding PAR BZIP transcription factor $(D b p)$ in the whole brain of rats was increased and the expression of period 2 (Per2) was reduced [14]. It's reported the changes in the expression of clock genes in whole brain, but it did not clarify the change in the central and peripheral circadian clock, nor on the hypoxia signaling pathway, nor did it study the effect of different propofol concentrations on the circadian clock. In peripheral tissues, liver is an important metabolic organ, and many basic metabolic pathways in liver (such as glycolysis, fatty acid metabolism, and cholesterol synthesis) are also rhythmic [10,15].

Considering the differences of central and peripheral clock, as well as the influence of propofol on intrinsic circadian clock and hypoxic condition of animals, this study aims to investigate the effect of different concentrations of the general anesthetic propofol on the circadian clock of mammalian central (hypothalamus) and peripheral (liver) tissues, as well as the hypoxia signaling pathway. The results are expected to help guide and optimize clinical anesthesia, especially for the patients with liver diseases.

\section{Methods}

\section{Experimental animals, cell lines, reagents and consumables}

Eight-week old male C57BL/6J mice (Model Animal Research Center, Nanjing, China) and PER2::LUC mice (Jackson Laboratory) were housed in a specific-pathogen-free (SPF) environment under a $12 \mathrm{~h}$ light/12 h dark cycle with free access to food and water. The U2OS cell line expressing Per2:dLuc was a gift from Professor Steve Kay of the University of California, San Diego. The main reagents and consumables included Dulbecco's Modified Eagle's Medium (DMEM) powder (Sigma-Aldrich), DMEM liquid basal medium, fetal bovine serum, B27 supplement 50x, gentamicin, penicillin-streptomycin, HEPES, $7.5 \% \mathrm{NaHCO}_{3}$ buffer, $0.25 \%$ trypsin, RNase-free water, TRIzol, $3.5 \mathrm{~cm}$ cell culture dishes with glass covers (Thermo Fisher Scientific), RNA reverse transcription kit PrimeScript ${ }^{\text {TM }}$ RT Master Mix (TAKARA), 
KAPA SYBR FAST Real-time PCR Master Mix (Kapa Biosystems) as the real-time polymerase chain reaction (PCR) kit, D-luciferin (Gold Bio), and 0.45 filters (Millipore).

\section{Anestheic exposure}

Eight-week old male C57BL/6J mice were randomly allocated to $10 \mathrm{mg} / \mathrm{kg}$ propofol $(\mathrm{n}=4), 20$ $\mathrm{mg} / \mathrm{kg}$ propofol $(\mathrm{n}=4)$ or vehicle (saline, $\mathrm{n}=8)$ treatment groups. Tail vein injection was performed at ZT10, and the tail vein injection with the same volume of normal saline was given to the mice in the control group. The anesthetic level of loss of righting reflex (LORR) was determined in mice administered propofol. All animals were sacrificed by cervical dislocation.

\section{Monitoring the circadian rhythm of U2OS cells}

3.1. Preparation of DMEM: $50 \mathrm{~mL}$ of fetal bovine serum and $5 \mathrm{~mL}$ of penicillin-streptomycin were added to $500 \mathrm{~mL}$ of liquid DMEM.

3.2. Preparation of $2 \times$ DMEM: A total of $470 \mathrm{~mL}$ of sterile water, $10 \mathrm{~mL}$ of $1 \mathrm{M} \mathrm{HEPES}, 10 \mathrm{~mL}$ of penicillinstreptomycin, $5 \mathrm{~mL}$ of $7.5 \% \mathrm{NaHCO}_{3}$ buffer and $500 \mathrm{mg}$ of gentamicin were added, in order, to DMEM powder (amount required for $1 \mathrm{~L}$ of $1 \times \mathrm{DMEM}$ ). The $\mathrm{pH}$ was adjusted to 7.2-7.4, and a final volume of 500 $\mathrm{mL}$ was obtained.

3.3. Preparation of $X M$ medium: A total of $25 \mathrm{~mL}$ of $2 \times \mathrm{DMEM}, 1 \mathrm{~mL}$ of $\mathrm{B} 27$ supplement $50 \times, 500 \mu \mathrm{L}$ of $100 \mathrm{mM}$ D-luciferin and $24 \mathrm{~mL}$ of sterilized water were mixed.

3.4. LumiCycle analysis: U2OS cells were seeded in a $3.5 \mathrm{~cm}$ culture dish. The medium was replaced with $1,200 \mu \mathrm{L}$ of XM medium. The culture dish was covered with a piece of glass (diameter, $4 \mathrm{~cm}$ ) and sealed using Vaseline; The plate was then placed in a LumiCycle for recording.

3.5. Tecan microplate reader analysis: U2OS cells was added to a 96-well plate. The medium in each well was aspirated, and $100 \mu \mathrm{L}$ of XM was added to each well. After sealing with a membrane, the plate was placed in a Tecan.

\section{Quantitative real-time polymerase chain reaction (qRT-PCR)}

Mice were sacrificed by cervical dislocation. The hypothalamus (including the SCN) and the liver were collected. RNA was extracted from the obtained tissues using TRIzol. The extracted RNA was reverse transcribed using $5 \times$ PrimeScript $^{\mathrm{TM}} \mathrm{RT}$ Master Mix. PCR was conducted using a CFX96 real-time PCR system $\left(95^{\circ} \mathrm{C}\right.$ for $3 \mathrm{~min}, 95^{\circ} \mathrm{C}$ for $3 \mathrm{~s}$, and $60^{\circ} \mathrm{C}$ for $30 \mathrm{~s}$ ( 40 cycles)) to detect the expression of clock genes (the primer sequences are shown in supplementary data).

\section{Monitoring the circadian rhythm in ex vivo liver tissue of mice}

A total of $1,200 \mu \mathrm{L}$ of XM medium was added to a $3.5 \mathrm{~cm}$ culture dish, and a tissue culture membrane (pore size, $0.45 \mu \mathrm{m}$ ) was placed in the dish (avoiding bubbles). Mice were sacrificed by cervical 
dislocation. A small piece of liver tissue was from the edge of the liver and transferred onto the membrane. The dish was sealed with a piece of glass and placed in a LumiCycle.

\section{Data analysis}

The recorded data were analyzed using LumiCycle Analysis software. The results from the Tecan microplate reader were exported using Excel. Statistical significance was determined using two-sided Student's tests, and differences with $P<0.05$ were considered significantly different $\left({ }^{\star} \mathrm{p}<0.05,{ }^{\star *} \mathrm{p}<0.01\right)$. All data were plotted with GraphPad Prism 7.

\section{Results}

\section{Propofol changed the amplitude of Per2 in U2OS cells}

To verify whether propofol has an effect on circadian clock and to determine the effect of different concentrations of propofol on circadian clock, human myeloma U2OS cells, which are the most widely used in circadian clock studies, were used. U2OS cells after the stable transfection of Per2:dLuc were used as a reporter system [16], and the dynamic change in the fluorescence signal was used to analyze the changes in the oscillation of Per2 after propofol was applied to the U2OS cells. The U2OS cells were seeded into a 96-well plate. Propofol was added to XM medium to prepare a mother liquor with a final concentration of $50 \mu \mathrm{M}$. The solution was sequentially diluted to $0.78 \mu \mathrm{M}$ in a 2 -fold concentration gradient, and the obtained solutions were added to each well. After sealing the plate, the cells were placed in a Tecan to record the oscillation of Per2 in the U2OS cells. The results showed that compared to the control treatment, the treatment with propofol solution at a concentration of $1.56 \mu \mathrm{M}$ or higher could affect the amplitude of Per2 (Figure 1A). To further determine the effect of propofol on the amplitude of Per2, propofol treatment was repeated with confluent U2OS cells in a $3.5 \mathrm{~cm}$ dish to record Per2 oscillation for 4-5 days in a LumiCycle (Figure 1B). The data were exported to analyze the changes in the amplitude and period of Per2 in U2OS cells treated with different concentrations of propofol. The results showed that compared to the control treatment, $1.5 \mu \mathrm{M}$ propofol caused a slight increase in the amplitude of Per2 in the cells, further increase in the concentration of propofol caused a decrease in the amplitude of Per2 (Figure 1C); the period of Per2 in the U2OS cells in the control group and the experimental group have no significant changes (Figure 1D).

\section{Propofol at a high concentration prolonged the period of Per2 in ex vivo liver tissue}

After determining that propofol affects the oscillation of Per2 in cells, to investigate whether propofol directly affects the circadian clock of ex vivo liver tissue without the $S C N$, liver tissue from PER2::LUC transgenic mice were placed in a LumiCycle to record the oscillation of Per2. $10 \mu \mathrm{M}$ propofol was added to the medium at the peak and trough of Per2. The treated and untreated ex vivo liver tissues was continuously recorded in the LumiCycle. The medium was replaced with untreated (no propofol) medium after 3-4 days, and the recording was continued. The most significant effect occurred when propofol was added at the peak of Per2; $10 \mu \mathrm{M}$ propofol lengthened the period of Per2 in the ex vivo liver tissue by $5 \mathrm{~h}$ 
(Figure 2A). Treatment when the trough of Per2 lengthened the period of Per2 in the ex vivo liver tissue by $2 \mathrm{~h}$ (Figure 2B). Statistical analysis of all data showed that propofol treatment at the peak and trough of Per2 could lengthen the period of Per2 in ex vivo liver tissue (Figure 2C); no significant effect on amplitude was observed (Figure 2D).

\section{Propofol changed the expression of clock genes in in vivo liver tissue and hypothalamic tissue}

To investigate the effect of propofol on the circadian clock of in vivo central tissue and peripheral liver tissue, the expression of clock genes were detected in samples collected from mice after they were anesthetized with propofol. The circadian clock of hypothalamic tissue in mice is usually used as an indicator of central circadian clock. According to Figure 2, the effect of propofol on the circadian clock of ex vivo liver tissue was the most significant at the peak of Per2. Because the effect of propofol on mice was the most significant $2 \mathrm{~h}$ after the treatment was applied, the expression of Per2 in mouse liver reached the peak point at zeitgeber time (ZT)12; thus, tail vein injection of propofol at doses of $10 \mathrm{mg} / \mathrm{kg}$ $(n=4)$ or $20 \mathrm{mg} / \mathrm{kg}(\mathrm{n}=4)$ was performed at ZT10. The anesthetic level of loss of righting reflex (LORR) was determined in mice administered propofol [17], and the tail vein injection with the same volume of normal saline was given to the mice $(n=4)$ in the control group. At ZT12, liver and hypothalamus samples were collected to detect the expression of clock genes by qRT-PCR (including Per1, Per2, Dbp, nuclear receptor subfamily 1 group D member 1 (Nr1d1), brain and muscle ARNT-like 1 (Bmal1), clock circadian regulator (Clock), and cryptochrome circadian regulator 1 (Cry1)) and hypoxia inducible factor 1 subunit alpha (Hif-1a) and its response genes (including vascular endothelial growth factor A (Vegfa), Egl-9 family hypoxia inducible factor $1(E g \ln 1), E g \ln 2$, and $E g / n 3)$. The results showed that the expression of $D b p$ and Clock in liver tissue was significantly increased with $10 \mathrm{mg} / \mathrm{kg}$ propofol (Figure 3A), while the expression of clock genes in the hypothalamus did not significantly change (Figure 3B). There was no significant change in the expression of clock genes in liver tissue with $20 \mathrm{mg} / \mathrm{kg}$ propofol (Figure 3C). The expression levels of the clock genes $\mathrm{Cry} 1, \mathrm{Dbp}, \mathrm{Nr1d1}$ and Clock in the hypothalamus were significantly decreased, while the expression levels of the hypoxia-related genes Hif-1a, EgIn1, EgIn2, and EgIn3 were significantly increased (Figure 3D).

\section{Discussion}

In this study, cells harboring the Per2 promoter-driven luciferase reporter were first used to reveal that the anesthetic agent, propofol, can affect the circadian clock. Subsequently, we demonstrated that the impact of propofol on changing the circadian clock both ex vivo and in vivo using the liver, and hypothalamic tissues.

The results showed that when U2OS cells were treated with $1.5 \mu \mathrm{M}$ propofol, the amplitude of Per2 in the cells was increased, and the amplitude reduced as the propofol concentration increased, indicating that a higher concentration of propofol could weaken the clock, which may easily cause circadian clock disorders by external factors. So different concentrations of propofol have different effects on the circadian clock of Per2 in cells. 
Thereafter, $1.5 \mu \mathrm{M}$ propofol was preferentially used to treat the ex vivo liver tissue of PER2::LUC mice. Surprisingly, our results suggested that $1.5 \mu \mathrm{M}$ propofol had little, if any impacts on the phase, period and amplitude of Per2 oscillation. However, based on experience in the clinical use of propofol for long-term sedation, the concentration of propofol was increased to $10 \mu \mathrm{M}$. Our further results showed that $10 \mu \mathrm{M}$ propofol significantly lengthened the period of Per2 in ex vivo liver tissue, indicating that a higher concentration of propofol can indeed affect the clock in liver tissue without the SCN. The lengthening of this period may lead to nonsynchronization of the circadian clock of liver tissue with the external day and night cycle, thus affecting the normal metabolism of the liver.

The expression of clock genes and hypoxia-inducible factor Hif-1a as well as its response genes in liver and hypothalamus were detected $2 \mathrm{~h}$ after mice were treated with $10 \mathrm{mg} / \mathrm{kg}$ propofol, $10 \mathrm{mg} / \mathrm{kg}$ propofol caused a significant increase in the expression of the liver clock genes $D b p$ and Clock, and the expression of $\mathrm{Cry} 1, \mathrm{Bmal1}$ and $\mathrm{Nr} 1 \mathrm{~d} 1$ showed an increasing trend, but with no significant effect on the expression of hypothalamic clock genes. That is, $2 \mathrm{~h}$ after anesthetizing mice with $10 \mathrm{mg} / \mathrm{kg}$ propofol, the influence on the liver tissue was dominant. The increased expression of $D b p$ can affect the circadian feedback loop of liver tissue. And the change in the expression of the clock genes in liver correlates with the development of liver diseases. The clock gene Cry 1 can regulate the activity of $\mathrm{G}$ protein coupled receptors, and the increase in the expression of liver $\mathrm{Cry} 1$ can lower the blood glucose level and improve insulin sensitivity in type 2 diabetic mice [18]. When treated with $10 \mathrm{mg} / \mathrm{kg}$ propofol, all the experimental mice just reached the level of LORR. Furthermore, it was reported that the effective concentration of propofol to just reach LORR in mice was $1.5 \mu \mathrm{M}$. Considering the finding that $1.5 \mu \mathrm{M}$ propofol increased the amplitude of Per2 in U2OS cells, the effective concentration of propofol is approximately $1.5 \mu \mathrm{M}$, which can strengthen the circadian clock of cells and peripheral (liver) tissue of the body.

When the dose of anesthetic propofol was increased to $20 \mathrm{mg} / \mathrm{kg}$, the expression of clock genes in liver tissue showed no significant change. The above results indicated that $10 \mu \mathrm{M}$ propofol can lengthen the period of ex vivo liver tissue; therefore, it is suspected that a high concentration of propofol might affect the circadian clock of in vivo liver tissue through multiple pathways, thus reaching an equilibrium to a certain extent. The expression of the clock genes Cry $1, D b p, N r 1 d 1$ and Clock in the hypothalamus were significantly decreased, indicating that when the concentration of propofol increased to $20 \mathrm{mg} / \mathrm{kg}$, the effect of propofol on the central clock was dominant. Additionally, $20 \mathrm{mg} / \mathrm{kg}$ propofol significantly increased the expression of the hypoxia-related genes Hif-1a, EgIn 1, EgIn2 and EgIn3 in the hypothalamus. Studies have confirmed that Hif-1a binds directly to the promoter region of Per2 to affect its expression [11]; therefore, it is hypothesized that the treatment with propofol at a high concentration for $2 \mathrm{~h}$ may affect hypothalamic clock genes of mice by activating the hypoxia signaling pathway, which can affect the expression of Per2 and affect the entire feedback loop, thereby significantly reducing the expression of a large number of clock genes. The reduction in hypothalamic clock genes will affect clockcontrolled genes, which will, in turn, affect the metabolism and periodic activities of the body [19].

\section{Conclusions}


Summarizing the above results, it was found that the general anesthetic propofol could change the normal circadian clock of in vivo and ex vivo mammalian peripheral (liver) tissue. Additionally, propofol at a lower concentration (for example the dose for anesthesia for painless gastrointestinal endoscopy) had a dominant effect on the peripheral (liver) tissue of the body and could strengthen the circadian clock of peripheral (liver) tissue. At higher propofol concentrations (for example the dose for intraoperative and postoperative long-term perfusion), the central circadian clock is dominant; thus, the expression of clock genes is inhibited, and the central circadian clock is weakened. The findings suggest that in clinical anesthesia, the long-term use of propofol should be avoided, to reduce the adverse effects of propofol on the central and peripheral circadian clock of patients, thereby reducing adverse effects on the postoperative prognosis of patients.

\section{Abbreviations}

Dbp : D-box binding PAR BZIP transcription factor

Clock: clock circadian regulator

Cry1: cryptochrome circadian regulator 1

Nr1d1: nuclear receptor subfamily 1 group $\mathrm{D}$ member 1

Hif-1a: hypoxia inducible factor 1 subunit alpha

Per2: period circadian rhythm 2

Bmal1: brain and muscle ARNT-like 1

Vegfa : vascular endothelial growth factor A

$E g \ln 1, E g / n 2$, and $E g \ln 3$ : Egl-9 family hypoxia inducible factor 1, 2, 3

SCN : suprachiasmatic nucleus

DMEM : Dulbecco's Modified Eagle's Medium

PBS: Phosphate buffered saline

\section{Declarations}

\section{Ethics approval and consent to participate}

All experiments with mice were performed following the guideline of the Institutional Animal Care and Use Committee (IACUC) at NIBS. The current study did not involve human participation, human data or human tissue. 
Availability of data and materials

The datasets used and/or analyzed during the current study are available from the corresponding author on reasonable request.

Consent for publication

Not Applicable

\section{Competing interests}

There are no conflicts of interest to declare.

\section{Funding}

This work was supported by the National Science Foundation of China [grant 81370210] (HH).

\section{Authors' contributions}

HH, TDY, EEZ and SQL designed research. HNT and ZQY performed research. HNT and QR analyzed research. XWZ, YJC writing assistance. All authors read and approved the final manuscript.

\section{Acknowledgements}

This work was supported by the National Science Foundation of China [grant 81370210] (HH). We thank Di Sang, Dapeng Ju and Long Mei from National Institute of Biological Sciences, Beijing, for experiment advising and writing assistance.

\section{References}

1. Montaigne D, Marechal X, Modine T, Coisne A, Mouton S, Fayad G, Ninni S, Klein C, Ortmans S, Seunes $\mathrm{C}$ et al: Daytime variation of perioperative myocardial injury in cardiac surgery and its prevention by Rev-Erba antagonism: a single-centre propensity-matched cohort study and a randomised study. The Lancet 2017.

2. Hastings MH: Circadian clocks. Current biology : CB 1997, 7(11):R670-672.

3. Bass J: Circadian topology of metabolism. Nature 2012, 491(7424):348-356.

4. Golden SS, Canales SR: Cyanobacterial circadian clocks-timing is everything. Nature reviews Microbiology 2003, 1(3):191-199.

5. Dunlap JC: Molecular bases for circadian clocks. Cell 1999, 96(2):271-290.

6. He B, Nohara K, Park N, Park YS, Guillory B, Zhao Z, Garcia JM, Koike N, Lee CC, Takahashi JS et al: The Small Molecule Nobiletin Targets the Molecular Oscillator to Enhance Circadian Rhythms and Protect against Metabolic Syndrome. Cell metabolism 2016, 23(4):610-621. 
7. Takahashi JS: Transcriptional architecture of the mammalian circadian clock. Nature reviews Genetics 2017, 18(3):164-179.

8. Balsalobre A, Brown SA, Marcacci L, Tronche F, Kellendonk C, Reichardt HM, Schutz G, Schibler U: Resetting of circadian time in peripheral tissues by glucocorticoid signaling. Science (New York, NY) 2000, 289(5488):2344-2347.

9. Yagita K, Tamanini F, van Der Horst GT, Okamura H: Molecular mechanisms of the biological clock in cultured fibroblasts. Science (New York, NY) 2001, 292(5515):278-281.

10. Takahashi JS, Hong HK, Ko CH, McDearmon EL: The genetics of mammalian circadian order and disorder: implications for physiology and disease. Nature reviews Genetics 2008, 9(10):764-775.

11. Wu Y, Tang D, Liu N, Xiong W, Huang H, Li Y, Ma Z, Zhao H, Chen P, Qi X et al: Reciprocal Regulation between the Circadian Clock and Hypoxia Signaling at the Genome Level in Mammals. Cell metabolism 2017, 25(1):73-85.

12. Touitou Y, Mauvieux B, Reinberg A, Dispersyn G: Disruption of the circadian period of body temperature by the anesthetic propofol. Chronobiol Int 2016, 33(9):1247-1254.

13. Challet $E$, Gourmelen S, Pevet P, Oberling P, Pain L: Reciprocal relationships between general (Propofol) anesthesia and circadian time in rats. Neuropsychopharmacology 2007, 32(3):728-735.

14. Yoshida Y, Nakazato K, Takemori K, Kobayashi K, Sakamoto A: The influences of propofol and dexmedetomidine on circadian gene expression in rat brain. Brain Res Bull 2009, 79(6):441-444.

15. Green CB, Takahashi JS, Bass J: The meter of metabolism. Cell 2008, 134(5):728-742.

16. Zhang EE, Liu AC, Hirota T, Miraglia LJ, Welch G, Pongsawakul PY, Liu X, Atwood A, Huss JW, 3rd, Janes $\mathrm{J}$ et al: A genome-wide RNAi screen for modifiers of the circadian clock in human cells. Cell 2009, 139(1):199-210.

17. Gelegen C, Miracca G, Ran MZ, Harding EC, Ye Z, Yu X, Tossell K, Houston CM, Yustos R, Hawkins ED et al: Excitatory Pathways from the Lateral Habenula Enable Propofol-Induced Sedation. Current biology : CB 2018, 28(4):580-587.e585.

18. Zhang EE, Liu Y, Dentin R, Pongsawakul PY, Liu AC, Hirota T, Nusinow DA, Sun X, Landais S, Kodama $Y$ et al: Cryptochrome mediates circadian regulation of cAMP signaling and hepatic gluconeogenesis. Nat Med 2010, 16(10):1152-1156.

19. Zhang EE, Kay SA: Clocks not winding down: unravelling circadian networks. Nat Rev Mol Cell Biol 2010, 11(11):764-776.

\section{Figures}


(A)

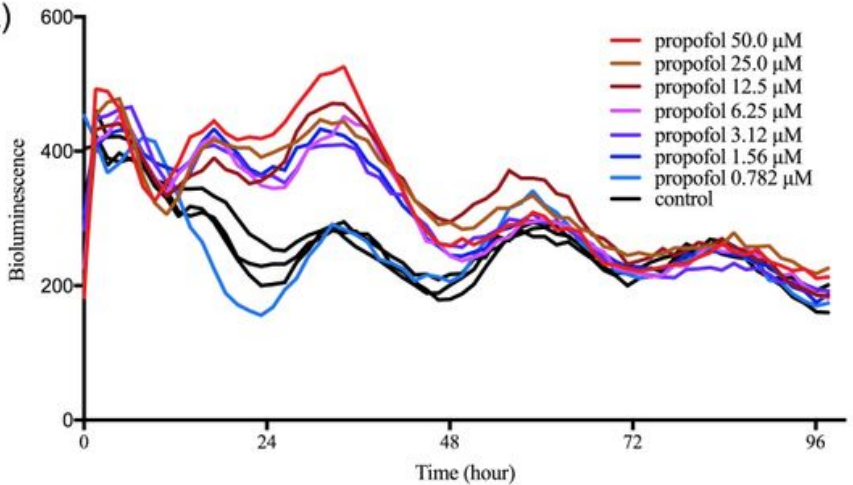

(C)

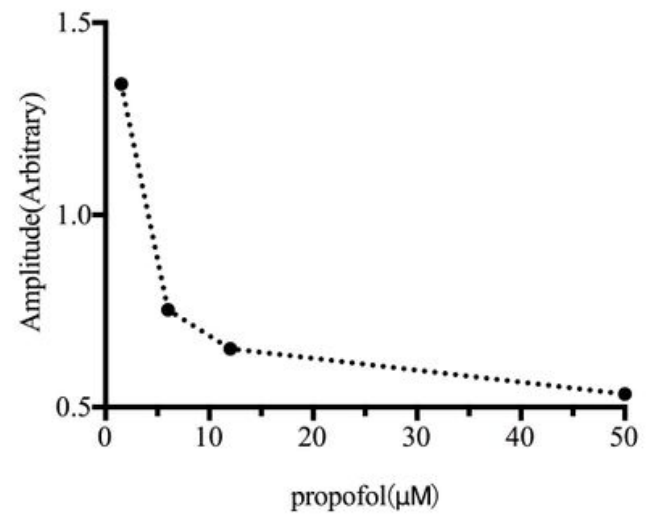

(B)

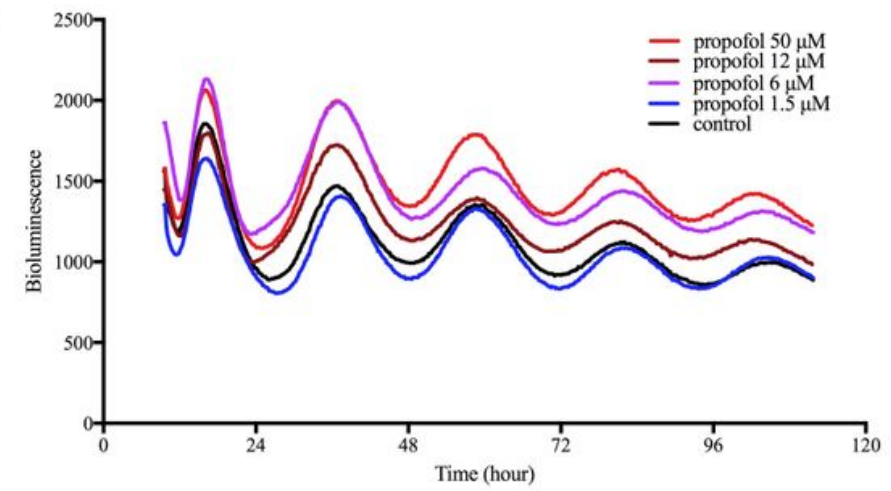

(D)

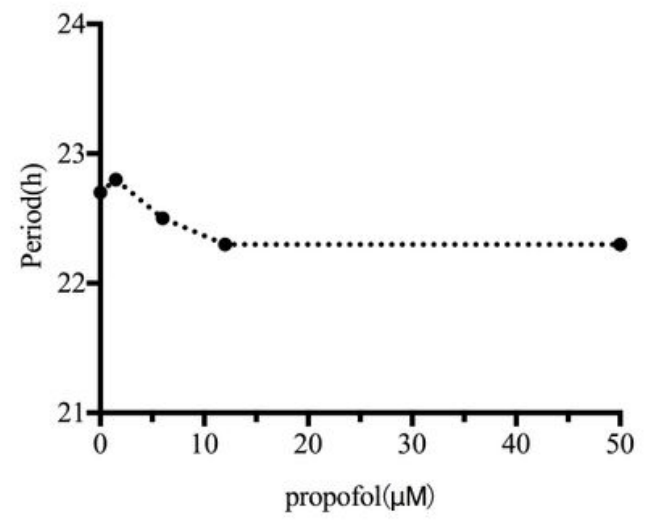

Figure 1

Propofol changed the amplitude of Per2 in human myeloma U2OS cells. (A) Tecan and (B) LumiCycle recorded the oscillation of Per2 in U2OS cells treated with different concentrations of propofol. The amplitude and period of Per2 in U2OS cells treated with propofol at various concentrations detected using the LumiCycle analysis software showed that (C) as the concentration of propofol increased, the amplitude of Per2 reduced; (D) treatment with propofol at different concentrations caused no significant changes in the period of Per2. 
(A)

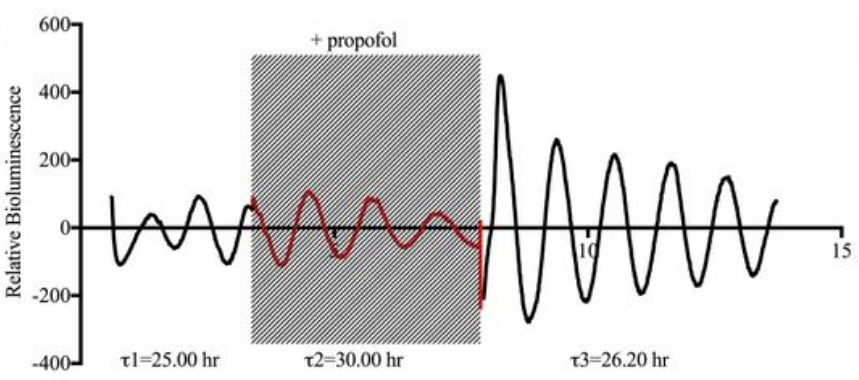

(C)

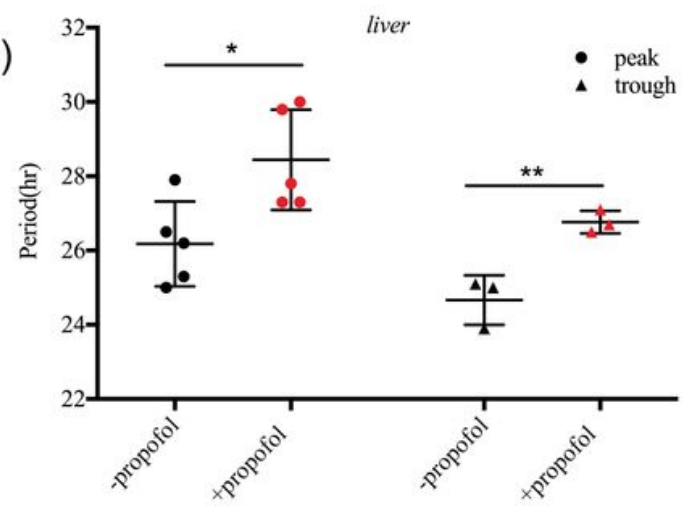

(B)

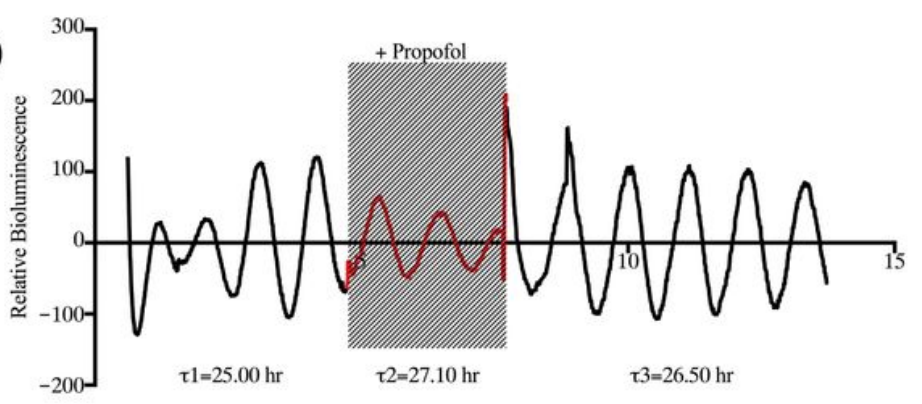

(D)

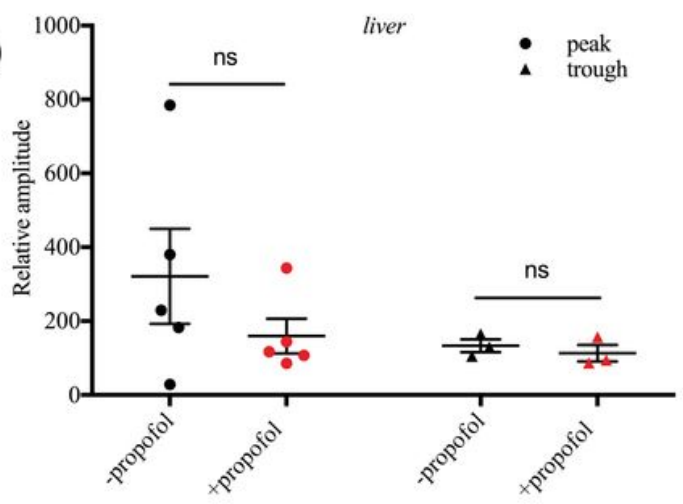

Figure 2

Propofol lengthened the period of Per2 oscillation in ex vivo liver tissue. (A) Adding $10 \mu \mathrm{M}$ propofol at the peak of Per2 lengthened the period of Per2 in ex vivo liver tissue by $5 \mathrm{~h}$. (B) Adding $10 \mu \mathrm{M}$ propofol at the trough of Per2 lengthened the period of Per2 in ex vivo liver tissue by $2 \mathrm{~h}$. The analysis of all data by the LumiCycle analysis software showed that (C) treatment with $10 \mu \mathrm{M}$ propofol at the peak and trough of Per2 could lengthen the period of Per 2 ; (D) treatment with $10 \mu \mathrm{M}$ propofol at the peak and trough of Per2 resulted in no significant change in the amplitude of Per2. Black indicates the period of Per2 in ex vivo liver tissue before the addition of propofol, red indicates the period of Per2 in ex vivo liver tissue after the addition of propofol; circles indicate the peak of Per2, and triangles indicate the trough of Per2 $(n>3$, $\left.{ }^{*} \mathrm{P}<0.05,{ }^{\star *} \mathrm{P}<0.01\right)$. 
(A)

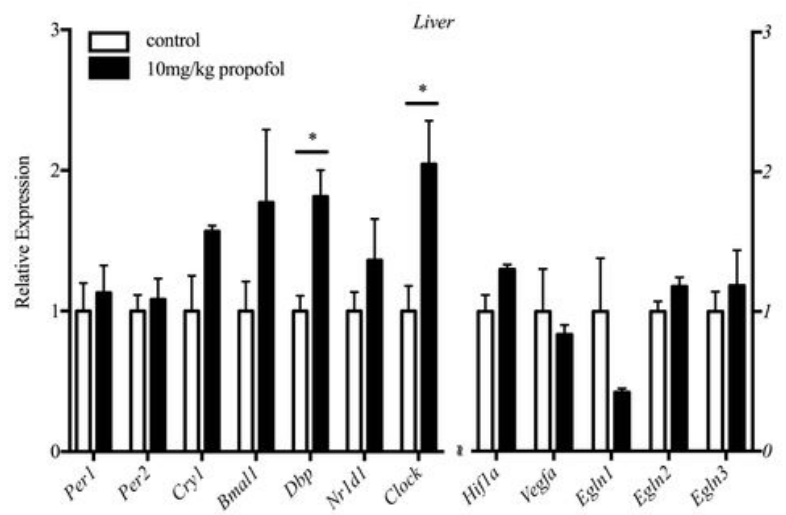

(C)

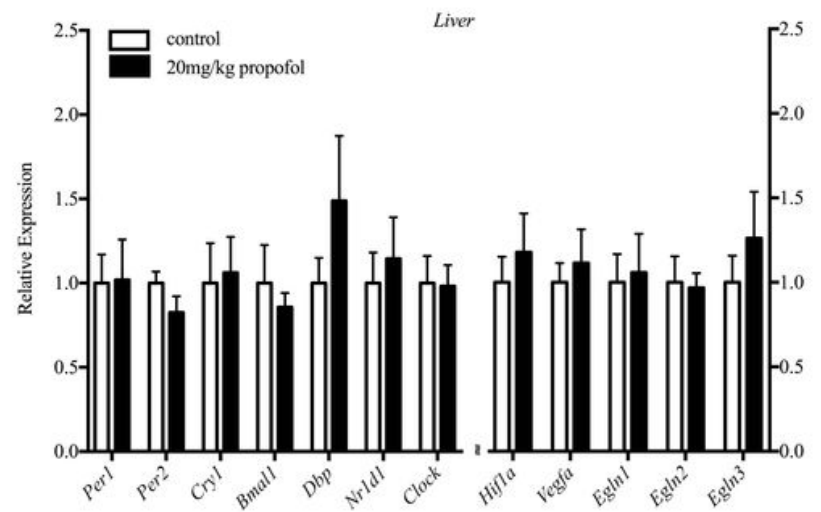

(B)

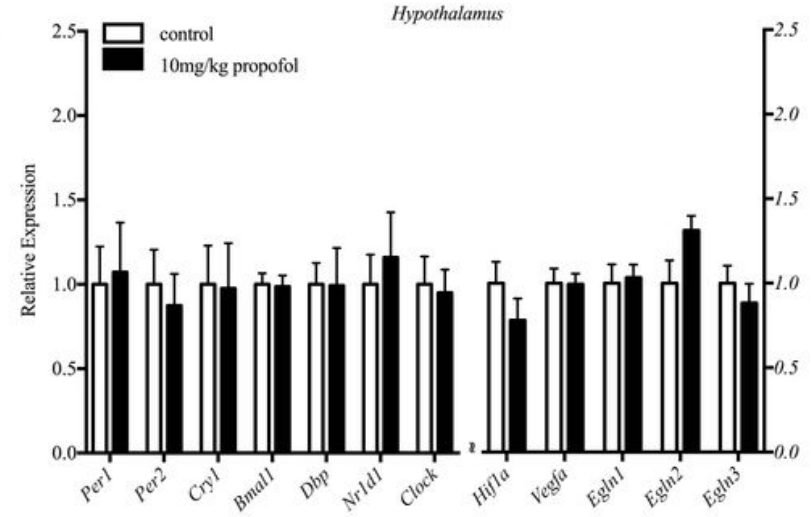

(D)

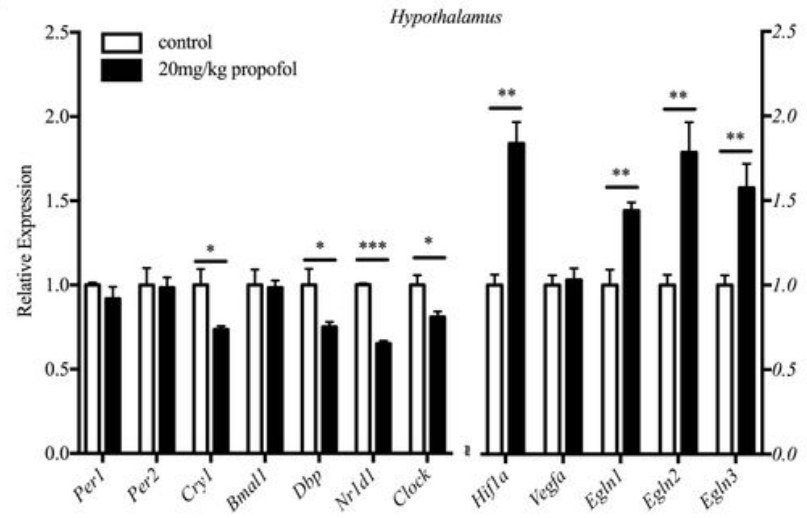

Figure 3

Propofol changed the in vivo expression of clock genes in central tissue and peripheral tissue. (A) Compared with those in the control group, the expression of Dbp and Clock in the liver tissue of the experimental group were significantly higher; (B) There was no significant difference between the control group and the experimental group in the hypothalamus. (C) There was no significant difference between the control group and the experimental group in the liver tissue; (D) The expression of the clock genes Cry1, Dbp, Nr1d1 and Clock in the hypothalamus were significantly decreased, and the expression of the hypoxia-related genes Hif-1a, Egln1, Egln2 and Egln3 were significantly increased $(n=4, * P<0.05$, $* * \mathrm{P}<0.01)$.

\section{Supplementary Files}

This is a list of supplementary files associated with this preprint. Click to download.

- checklist4.10.docx

- supplementary4.10.docx 